\title{
The Consumer Perspectives on Service Quality and Performance of Road Infrastructure Assets
}

\author{
Katharina Priyatiningsih \\ Student of Management Science Doctorate Program - \\ School Of Post Graduate \\ Universitas Pendidikan Indonesia \\ E-mail : katrinapry@gmail.com,katrinapry@student.upi.edu
}

\author{
Ratih Hurriyati \\ Lecturer of Business and Economic Education Faculty \\ Business and Management Master Program \\ and Management Science Doctorate Program \\ School Of Post Graduate -Universitas Pendidikan Indonesia \\ E-mail : ratih@upi.edu
}

\begin{abstract}
Road infrastructure assets have an important role, in the economic, social, political, and security in achieving the prosperity of society. The damaged roads become one of the obstacles to development and an indication of the cause of deficiencies in the quality service and performance of infrastructure assets. This study aims to determine the consumer's perspective (road users) as stakeholders in assessing the quality of services through technical and functional and the asset's performance through physical performance, functional, and utilities. The assessment is based on the consumer's perspective in this research are road users. The respondents consisted of driver freight, forwarding company (people or goods), and conducted by the descriptive method. The results showed that refer to ServPerf, the quality of technical services had a value that is stronger than the functional service quality. However, in the performance of assets, strong ratings sequentially occur in utility, physically, and functionality. The consumer perspective as road users, has a technical assessment that the road infrastructure assets as an outcome more dominant to provide quality service, whereas for asset performance, utility considered more powerful. This describes, how intensive in the use of road infrastructure assets in meeting the objectives of service delivery.
\end{abstract}

Keywords : service quality, asset's performance, road infrastructure assets

\section{INTRODUCTION}

The strategic role of a reliable infrastructure asset is to build the nation for the quality of life improvement [1], and this road infrastructure asset development has a positive influence for the increase in investment. Road infrastructure asset is a static system (can be in the form of a network) for serving certain community as a facility of a region as well as a encouraging asset in a modern life with an expected service level. In a system, the entire asset will be maintained to be always in certain service level with replacements or updates on its supporting network. Park stated that infrastructures, such as road, dam, airport, road network, or irrigation, were strategic national assets, which were related to public welfare as an important indicator of national competition and economic growth [2].

The service level needed by the society is with an efficient funding through procurement, acquisition, maintenance, operation, rehabilitation and liquidation of assets for user community or consumer. The service of road provision as infrastructure is either an intangible or tangible activity with the main focus of serving consumers, whether it is accompanied by certain goods or not.

Research on the perception of the road by road users on quality regarding maintenance and service done on the highway, with the results of the service, security and reliability, are perceived by road users to measure of highway maintenance [3]. Performance measurement infrastructure assets on previous research through an assessment of the level of performance of the asset based on the perception of the end user of such assets through three essential aspects namely, technically and functionally appropriate image dimensions of each performance [4]. Two of these studies were equally based consumer perceptions, and measuring service quality and performance.

The gap of this research is a road infrastructure is a path non-toll (non- highway), which aims to better its management services for purposes not commercial, as well as more operational activities highlight not only the maintenance of its assets. The problem is whether the road service as infrastructure has met the needs of consumers (qualified) or not by knowing how the consumers perspective on the road service quality received is. The answer depends on the consumer's subjective rating. The consumer's perspective on the service quality of the infrastructure assets is essentially a thorough assessment on the excellence of a service. For the road asset administrators, it can be used to provide transportation infrastructure facility by striving to make the road asset more superior than the competitor's (rail way or space) which is through providing equally service that can meet the level of consumer's interest.

Oliver cites from Berry and Czepiel, Dagger, et al. there was a relevance with the service provider (asset management) in minimizing the risks received when evaluating services as intangible-products and giving the consumers (road users) valuable benefits [5]. So in order to fulfil the interest level through the consumer's perspective, the administrator of the road infrastructure assets can prioritize more on intangibleproduct or service to the benefit value through service quality.

Service quality is the comprehensive characteristic and feature of the service which is started from the ability to meet the needs of consumers and ended by the consumer's 
satisfaction through the service quality received [6]. Kotler defined service as 'any behavior or act based on a contact between two parties: the provider and the receiver, and the essence of this reciprocal process in intangible [7]. The service quality that is in the form of behavior or act between consumers, and service provider is a consumer's perception which influences the formation of consumer's satisfaction. Consumers perceived quality is not a realistic or objective service quality even though it can be used as a consideration for consumers to make the buying decision.

The specific performance measurement characteristics are more apparent to service operations level and there are three distinctive features of service performance measurement. First, the contingency perspective stresses a need to consider the characteristics of different service contexts; second, the customer-orientation implies that the measurement should also cover customers' actions during the service operation as well as the impacts of service operations; and third, the systemic perspective proposes that performance measurement should encompass all actors participating to service operations [8].

It needs an evaluation of the service program from the asset management which covers the evaluation of asset performance to decide whether the service performance of the asset is adequate for supporting the service provision strategy that has been conducted [9].

Referring to Logue and Avery, a excellent performance from the road authority is by maintaining the excellent performance as well as the good appearance without degrading the structure value or decreasing the lifetime of the road asset [10]. The most suitable method unites the service delivery needs from the consumers with the asset performance which is evaluated more related to the asset administrator as an asset concept. This concept acts as a strategic approach in the infrastructure asset management as a holistic process which has a characteristic and is designed to meet the organization's objective through operational delivery with a clear responsibility between the asset owner, asset administrator and service [11].

This fundamental research is eventually able to know how to manage a road infrastructure asset through the development of an asset management and service management model, which is by looking at how the correlation between the service quality, and the performance evaluation of an asset works. The identification of problems of this paper is to know how the consumer's perspective is about the service quality and the performance of the road infrastructure asset.

\section{LITERATURE REVIEW}

\section{A. Consumers Perspective}

Consumer's perspective is a perspective of the consumption result and an 'experience' of consumers in consuming a product, including a service. The consumers do not only decide whether there is a relationship or not, but also decide to share their 'experience' with other consumers [12]. The study performed by Sandstrom et al. in a product of telecommunication service learned about how the involvement of consumers in the process of idea for a service based on a new technology can contribute to the impassioned and working aspect growth as the entirety of consumers 'experience'[13]. In determining the service quality and performance from the road infrastructure asset, it needs consumer's perspective to share the perspective in the process of service delivery idea through emotional and functional aspects eventually. The road performance can be measured using three perspectives, including sub-sector, provision, and road-users. It is this road-users perspective that will be used in the measurement of road performance and service quality [14].

\section{B. Service Quality of Road Infrastructure Assets}

The infrastructure asset managed would issue product diversification, trade development, construction equalization and poverty alleviation, as well as quality of life improvement in general. Besides, infrastructure asset has a strategic value for the development of a nation because its quality of life is marked by the condition of the infrastructure in that country [15]. Meanwhile, World Bank supported infrastructure as the main contributor for the growth and improvement of the standard of living in a country, so that the cooperation formed was aimed for improving the investment climate [16]. According to the rule standard, road classification is divided into two types, including state road and special road. State road is a road intended for public traffic, while specific road is a road which is built by an institution, company, individual, or community for their personal interests.

The concept and measurement of the perception about the service quality that is used by the researcher are the measurement from Gronroos (Nordic perspective) that defines the dimension of service quality in its entirety as technical and functional quality [17]. Measuring a service can mean assessing or comparing the performance of a service with a set of standards, which has been set before. So, a service quality is an assessment of how far a service is in accordance with what is supposed to be delivered to the customers. The involvement of the society and private party as stakeholders can direct the road infrastructure quality in correspond to the stakeholders' interests, as explained by Humplick and Peterson [18].

ServPerf as a service quality scale using the fundamental of customer's perception through the performance and scale result in the value of service quality entirely could be designed with the classification of the time and customers (based on demographic segmentation. Santos stated two dimensions of service quality, including incubates dimension, which was a more functional and active dimension which was more technical [19].

Sharabi quoted from The Gaps Model from Parasuraman one of which is the performance gap, which is the difference between service standards and service actually, which is available and predicted to happen due to the short life of resources, incompatibility of the supply and demand, or the management process that is less appropriate[20]. Infrastructure asset, including road, is a form of service whose performance can be measured and indicated to have the performance gaps that can be measured by performance evaluation. 


\section{Performance of Road Infrastructure Assets}

Infrastructure management is needed for the purpose of achieving the infrastructure service level that is needed by the society through efficient ways in the management of the assets, starting from the planning of needs, procurement, operation, maintenance, until liquidation. The term infrastructure management itself is used for the same thing, especially in asset management whose scope is used broader, just like the one used in a professional society: in this context, infrastructure is a broad term which refers to road and train, water, electricity, and other assets.

Infrastructure provision is the responsibility and role of the government as the policy key holder because basically, infrastructure is an asset which is established to provide services for the society, especially the infrastructures whose uses are free of charge, such as the roads that are not toll roads. The administrator of a road infrastructure assets faces a challenge, that is how to realize a reliable state transportation network (strong, secure, comfortable, and efficient) with limited resources (human resources, funds, and organizations), so that it can provide the benefits of synergistic and adequate transportation service as well as increasing accessibility and mobility of goods and services in order to improve national competitiveness. Infrastructure revamping keeps becoming a priority in sustainable development, especially revamping in quality and quantity as well as the needs to involve private parties and the society.

Infrastructure service is formulated in the Infrastructure Asset Management Plan which is classified into two levels, which are Community Levels of Service and Technical Levels of Service. Hartanto and Susilo (2001) measured road performance with three perspectives, which were sub-sector, provision, and road users, while the purpose of measuring service quality and its relationship with road, which would be used to measure the performance was from road user's perspective through five dimensions, which include the quality of service, mobility, visible risk, customer's cost, and the use of resources.[21]

Hariyono wrote about how asset performance measurement could be performed through asset performance evaluation, which was a part of the asset evaluation process, consisting of physical condition, functionality, utility, and condition [22]. The physical condition of an asset must be able to be used safely and effectively, meaning that the asset must be maintained to be always in adequate condition to be used according to the purpose that has been set and meet the relevant health and safety standards. If the asset does not experience any problem, then the ability of the asset to provide services will be in accordance with the required standards. The functionality of an asset is the measurement of the effectiveness of an asset in supporting the activities that will be performed. The functionality of an asset should be reviewed periodically to identify a significant influence of the service. Asset utilization is the measurement of how intensive an asset is used for meeting the purpose of service delivery. The financial performance of an asset must be evaluated for deciding whether the asset can give a healthy service economically or not.

\section{METHODOLOGY}

The research uses a descriptive method with the object of research is assets of road infrastructure in one region of the province through the measurement of the quality of services and to measure its performance. Sampling for all research activities conducted with stratified sampling with a respondent who engaged in user road infrastructure assets. The tools and instrument of data collection was done through the study of literature for secondary data as well as the interview, question form and survey for primary data. The whole process of data and analysis of the approach of many qualitative and quantitative. The research design compiled by identifying problems in research and resolved through a systems approach means that the overall goal of this research will be answered by learning, understanding, observing, and concluded that the system was built and graded road infrastructure assets through user a perception.

In order to find out about the quality of road service, it will be measured in two dimensions, which are technical quality and functional quality, while the performance of road infrastructure assets will be evaluated with four dimensions, including physical form, finance, function, and utility based on user's perception. The framework is presented in Figure 1.

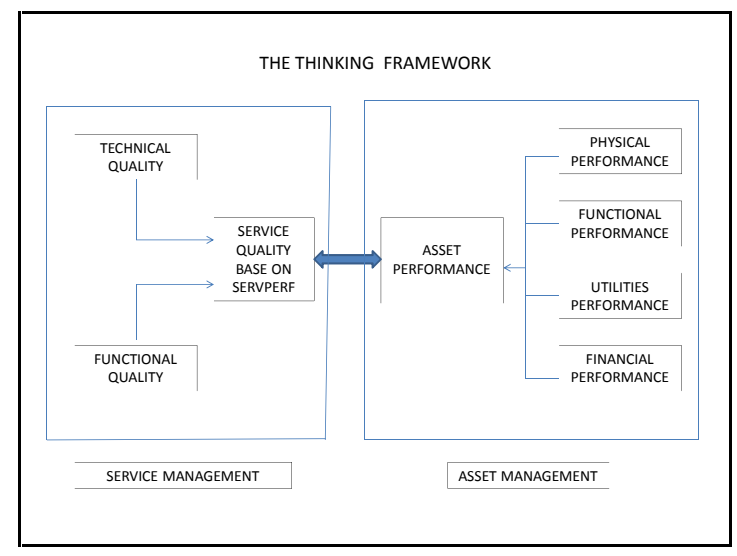

Fig. 1. The Thinking Framework (Data Processing Result, 2016)

Multiple data collection techniques were used in the data collection process that is the combination of both quantitative and qualitative methods, which includes focused interviews, case studies and observation. Interviews are conducted specifically to the road users of area on chosen high-rise road asset infrastructure. Road users were asked on the physically, functionally, utility, and quality of the road provided, as well as problems and improvements that have been needed for the roads. 80 sets of questionnaires were distributed to the companies of goods and passenger's transportation in a region, and 60 sets were returned for analysis. The authors personally distributed the questionnaires to the respondents. Sets of questionnaires with structured and semi-structured / openended questions were distributed to the respective road users to discover regularities among groups of maintenance management by comparison of answers to the same set of questions. We estimated a descriptive analysis model for service quality allowing the two dimensions of road services, 
and for performance allowing the three dimensions of road performances.

\section{RESULTS AND DISCUSSION}

\section{A. Measurement of Road Infrastructure Asset Service Quality}

According to the Nordic concept, then the measurement of service quality consists of technical quality and functional quality. The technological quality is the measurement of outcome/what, which is what can be delivered from the road infrastructure asset reliably and refers to the standards of road rules, which include plan speed, road width, road capacity, road entrance, intersection plot and U-turn facility, complementary buildings, road equipment, users in accordance with the function, and uninterrupted road.

Referring to the past research from Humplick and Peterson, the result of road service quality measurement is in accordance with the research result, in which the measurement of the road service quality shows that the technical quality has more expectations, and the functional quality is, on the contrary, in which it have fewer expectations of service quality [23] . Realized or not, road users have perspectives of road quality ranging from: the surface and function of road facility, safety risk, the easiness of using the facility in moving condition and risk of congestion as well as its prevention, user cost and avoidance of the vehicle operational cost. The last one is the environmental consideration of air and noise quality. This finding is supported by the research from Kang, which stated that customer perception about quality consists of two dimensions, including technical dimension and functional dimension [24]. The road performance in presenting the services to the customers or potential customers is influenced by how big the ability of a road infrastructure assets, which can be provided to meet the needs (knowing/skill) of the customers, besides it needs to be supported by the availability of other facilities and infrastructures, such as communication equipment, information, data, work environment, and so on.

\section{B. Measurement of Road Infrastructure Asset Performance}

The measurement of road performance evaluation consists of physical condition, functionality, utility, and economic condition. All performance dimensions consist of strong and durable enough indicators on the physical condition performance, functionality, and utility, while the financial performance is not measured. It is in line with the definition of infrastructure management, which states that the management of infrastructure assets is a certain term of asset management, which focuses on physical asset, not financial asset.

In the performance dimension of functionality, it is by $30 \%$ and the indicator shows that this measuring instrument is strong, and the remaining $70 \%$ is only strong enough to measure the performance of road functionally. The performance with this functional dimension measures the effectiveness of the road infrastructure asset in supporting the activities that will be conducted to observe and assess the asset functionality, with the result achievement through service delivery and functional character. The functional performance is a functional requirement which is established for the road that is built. In this research, the dominant indicator is the total trip per year/capacity, total congestion, and road function closing.

Utility performance dimensions which are measured from how intensive the road infrastructure asset is used to meet the purpose of service delivery with the criteria that take into account the potency of asset benefit/service in the service given, physical size of road capacity, and the use of an asset towards optimum availability of the asset related to the risk by $66.6 \%$, a strong and the remaining $33.3 \%$ that is strong enough.

Consumer perspective as a perspective of the result and experience in performing the consumption of an infrastructure asset product is between service quality and its performance. It can be concluded there is a moderate relationship between the two variables in several indicators is represented by: complementary buildings of road construction support, building road complements that are related to the road users for health, safety, order, and smoothness of traffic as well as the easiness in road traffic. Road users are classified based on each function of the road as artery road, local road and environmental road, the access to get information about road execution, as well as participating in the road execution, especially for road utilization and responsiveness, which is about getting a proper compensation caused by the errors in the construction of the road, as well as filing a lawsuit in court towards the losses caused by the construction of the road.

This condition is in accordance with the research conducted by Haas, Hudson and Tighe, which stated that there were several factors that were related to the benefits of public road customers and their interests as relationship decomposers between the two variables, namely ride quality, surface friction, noise, surface distress, surface drainage, user delays, life cycle, and structural adequacy [25].

The interests of stakeholders in the road infrastructure sector (Road Network Users, Road Transport Service Suppliers, Road Transport Policy Sectors and Institutions, and Road Network Suppliers) have a contradiction between interest and expectation, so that they cause the assessment and measurement of the performance dimensions to be varied. There are three aspects that must be able to be explained by a road administrator in the measurement of road management performance according to Talvitie, which are doing the right things (effective), doing things right (efficient), what external factor that comes out and how big its influence is towards the road sector [26].

\section{Measurement of Consumers Perspective bases on Service Quality and Performance of Road Infrastructure Asset.}

The result of consumer's perspective as a perspective of the consumption and an experience of road users in consuming a service of the roads showed:

1) Consumers have the perception that the qualities of the existing services on road infrastructure assets are generally stronger than technical functional. As a user of the way, they feel a stronger technical consumption without the linking function of perception of service quality road infrastructure 
assets. The explanation based on the concept that consumer involvement in the process of how the idea for the servicebased technology can contribute to the development of a functional aspect as temporary emotional experiences for consumers '

2) Consumers have the perception that the performance of existing services on the assets of the road infrastructure in the more powerful utility than physical and functional. As a user of the way they feel utilities stronger without linking physical perception and function of road infrastructure assets service performance. The explanation based on the concept, there are States. The utility was measured from how asset intensive road infrastructures are used to meet the goal of service delivery criteria the potential benefits of the asset/service in the services provided, including the physical size of road capacity and use of assets against optimally and its relationship with risk, as well as the effectiveness of the road infrastructure asset in supporting the activities as a function.

\section{CONCLUSION}

Asset management can be used in road infrastructure asset management, which is as the framework to optimize and perform the decisions of procurement, operation, maintenance, surveillance, update, improvement and liquidation of assets physically to provide the infrastructure that is secure and economic, so that it can influence the operational performance and profitability of the company that operates the asset [27]. The main purpose of asset management to help an organization in fulfilling the purpose of service provision effectively and efficiently, while the target of asset management is to achieve the best suitability between the asset and the strategy of service provision.

The quality of infrastructure asset service can be measured with technical quality and functional quality. The prominent indicator is in the technical quality, which is a plan that is in accordance with the specification of road provision as infrastructure, connection between the activity center from national scale to regional scale, complementary building for road construction support, building road equipment for safety/security/order/smoothness of traffic or easiness of traffic, as well as road utilization in correspond with its function. The indicator that measures the functional service quality which is dominated by receipts of service delivery gives added value, quality of the relationship between customers and provider, as well as accuracy, which includes integrated transportation system, delivery method of technical quality, and responsiveness.

The performance of a road infrastructure assets can be measured from its physical condition, which is related to public health and security, environmental hospitality and easiness, asset inspection in accordance with the requirements as well as the planning of asset condition in the future by looking primarily at the ascending road surface quality and road corridor quality. The dominant functional performance of the road infrastructure asset is in the complete amount of trip or capacity by the year, total congestion, and road function closing. The utility performance is represented by service delivery with the criteria that put into account the potency of benefit/service of the asset towards the service delivered, such as the physical size of the road capacity as well as the asset utilization towards optimum availability from the related asset.

The consumer's prospective basis on service quality, and performance have stronger perceptions on the technical service quality and have stronger perceptions on utility's performance of road infrastructure assets.

The advice from this research is that a deeper study is needed to know about the existence of a relationship between service quality and asset performance of road infrastructure, which is a part of asset-management strategy.

\section{ACKNOWLEDGMENT}

This research is a fundamental research program by 2013, and 2014 was carried out through the help of some parties. Thanks and our appreciation to the Directorate General of Higher Education of the Ministry of Research \& Technology and Higher Education- Republic of Indonesia, Research and Community Services Unit of Bandung State Polytechnic and School of Post Graduate University Pendidikan Indonesia

\section{REFERENCES}

[1] Wuritomo, Nugroho., The Strategy of Public Works Infrastructure Asset Management to Increase the Competitiveness of the Nation., Professional Education Journal - Pusbiktek-Ministry of Public Works of the Republic of Indonesia, 2008, Volume: 1 Number 16 March 2008. ISSN 1832-5568

[2] Park, Sanghoon., Sang I.Park and Sang-Ho Lee. Strategy on Sustainable Infrastructure Asset Management: Focus on Korea's Future Policy Directivity, Renewable and Sustainable Energy Reviews 62, 2016, Pp $710-722$

[3] Burde, Adrian., A Study on Road Users' Overall Perceptions of Highway Maintenance Service Quality and the Variables that Define the Highway Maintenance Service Quality Domain., Dissertation of Doctor of Philosophy in Civil Engineering. the Faculty of the Virginia Polytechnic Institute and State University, Blacksburg, Virginia, 2008

[4] Nik-Mata N. E. M., S. N. Kamaruzzamanb, M. Pitta., Assessing the Maintenance Aspect of Facilities Management through a Performance Measurement System: A Malaysian Case Study., The 2nd International Building Control Conference 2011, Procedia Engineering $20,2011,329-338$

[5] Oliver, Jason., The Consumer's Perspective on Evaluating Products: Service is The Key. Journal of Services Marketing. , Vol. 29 Iss 3, 2015

[6] Kotler Philip, John Bowen \& James Makens., The hospitality and Tourism Marketing., Edition In Indonesian Language, Jakarta: Pearson Education Asia Pte, Ltd. and PT Prenhallindo, 2002

[7] Mohammad, Anber Abraheem Shlash and Shireen Yaseen Mohammad Alhamadani., Service Quality Perspectives and Customer Satisfaction in Commercial Banks Working in Jordan., Middle Eastern Finance and Economics ISSN: 1450-2889 Issue 14 (2011)@ EuroJournals Publishing, Inc, 2011

[8] Jääskeläinen Aki and Harri Laihonen., Distinctive Features ff Service Performance Measurement., International Journal of Operations \& Production Management Vol. 34 No. 12, 2014 pp. 1466-1486

[9] Hariyono, Arik ., The Principle and Technique of the Country's Wealth Management., Jakarta: Ministry of Finance of the Republic of Indonesia General Financial Education and Training Agency, 2007

[10] Horak E, S Emery and A Agaienz., Key Performance Indicators for Road Infrastructure Asset Management by a Road Agency in a Large Local Authority., Meeting the Transport Challenges in Southtern 
Africa's Conference Papers., $20^{\text {th }}$ South African Transport Conference., South African : Document Transportation Technologies, 2001

[11] Houten, van T.P. and Linda L. Zhang., Managing Assets in The Infrastructure Sector., International Journal of Engineering Business Management, 2010, Vol. 2, No. 2 pp. 55-60

[12] Oliver, Jason., The Consumer's Perspective on Evaluating Products: Service is The Key. Journal of Services Marketing. , Vol. 29 Iss 3, 2015

[13] Sandstro"m Sara, Peter Magnusson and Per Kristensson., Increased Understanding of Service Experiences through Involving Users in Service Development., European Journal of Innovation Management Vol. 12 No. 2, 2009., pp. 243-25

[14] Hartanto , Budi and Yusak O. Susilo., Performance Indicators as A Measurement of Succesfull of Road Development., Proceedings of the Eastern Asia Society for Transportation Studies, Vol. 3, No. 1, October, 2001.

[15] Wuritomo, Nugroho., The Strategy of Public Works Infrastructure Asset Management to Increase the Competitiveness of the Nation., Professional Education Journal - Pusbiktek-Ministry of Public Works of the Republic of Indonesia, 2008, Volume: 1 Number 16 March 2008. ISSN 1832-5568

[16] ...., World Bank., The World Bank Approved a new Framework for The Development of Indonesia. News-Press Releases, Washington. December 1, 2015

[17] Brady, Michael K, and J.Joseph Cronin Jr., "Some New Thoughts on Conceptualising Perceived Service Quality: A Hierarchical Approach". Journal of Marketing, Vol 65. July 2001.

[18] Karlaftis, Matthew, dan Konstantinos Kepaptsoglou., Performance Measurement in the Road Sector: A cross-country review of Experience., International Transport Forum., Discussion Paper,No. 2012-10, October 2012

[19] Santos Jessica., From Intangibility to Tangibility on Service Quality Perceptions: A Comparison Study Between Consumers and Service
Providers in Four Service Industries., Managing Service Quality, 2002, Vol. 12 Iss: 5, pp.292

[20] Sharabi, Moshe and Moshe Davidow., Service Quality Implementation : Problems and Solutions., International Journal of Quality and Service Sciences Vol. 2 No. 2, 2010.pp $180-205$

[21] Hartanto, Budi and Yusak O. Susilo., Performance Indicators as A Measurement of Succesfull of Road Development., Proceedings of The Eastern Asia Society for Transportation Studies., Vol 3, No. 1, October 2001

[22] Hariyono, Arik ., The Principle and Technique of the Country's Wealth Management., Jakarta: Ministry of Finance of the Republic of Indonesia General Financial Education and Training Agency, 2007

[23] Humpick, Frannie and William D.O. Peterson., Framework of Performance Indicators for Managing Road Infrastructure and Pavements., in 3rd International Conference on Managing Pavements . pp. 123-133, 1994

[24] Kang, Gi-Du., The Hierarchical Structure of Service Quality: Integration of Technical and Functional Quality.,. Managing Service Quality. Vol. 16, No. 1, pp. 37-50. DOI: 10.1108/09604520610639955, 2006

[25] Haas, Ralph, W.Ronald Hudson, and Susan Tighe., "Maximizing Customer Benefits as the Ultimate Goal of Pavement Management", in 5th International Conference on Managing Pavements , 2001

[26] Karlaftis, Matthew, dan Konstantinos Kepaptsoglou., Performance Measurement in the Road Sector: A cross-country review of Experience., International Transport Forum., Discussion Paper,No. 2012-10, October 2012

[27] Prescott, Rasa Remenyte dan John Andrews ., Review of Infrastructure Asset Management Methods for Networked Systems., United Kingdom :Nottingham Transportation Engineering Centre, University of Nottingham, UK (www. nottingham.ac.uk), 2011 